\title{
A study of the incidence of epilepsy following ECT
}

\author{
D H R BLACKWOOD*, R E CULL†, C P L FREEMAN $\ddagger$, J I EVANS $\ddagger$, \\ AND C MAWDSLEY §
}

From the MRC Brain Metabolism Unit, University Department of Pharmacology*, Edinburgh, The Department of Medical Neurology, Royal Infirmary, Edinburght, The Department of Psychiatry, Royal Edinburgh Hospital $\$$, and the Department of Medical Neurology, Northern General Hospital, Edinburgh $\S$

SUM M ARY In a group of 166 patients who had received electroconvulsive therapy more than one year previously the prevalence of epilepsy did not differ significantly from that found in the community as a whole. The findings suggest that a kindling process is not a clinical hazard following repeated electrically induced seizures.

Meduna's hypothesis that there was an apparently reversible antagonism between the epileptic state and schizophrenia led to the development of convulsive therapy and its application to a wide range of clinical conditions. ${ }^{1}$ Early workers observed that the threshold to seizures (the minimum voltage required to elicit a convulsion) became elevated in patients undergoing convulsive treatment and it was proposed that electroshock treatment might even be useful in the management of patients with epilepsy. Several reports claimed a reduction in the frequency of fits in small numbers of patients with intractable epilepsy following treatment with electroshock therapy $^{2-4}$ and Kalinowski et $a l^{2}$ showed that an increase in seizure threshold could follow convulsions whether these were spontaneous or induced by Metrazol or electroshock. The clinical observations that convulsions may afford temporary protection against further fits was supported by experiments using rats $^{56}$ and cats. $^{78}$ Spontaneous fits also occurred in some cats during periods of daily electrical stimulation even when the seizure threshold was elevated and it was concluded that an epileptogenic process was taking place in addition to a threshold elevating effect. $^{7} 8$

The relation between electroconvulsive therapy and epilepsy remained controversial and Blumenthal ${ }^{9}$ reviewing a large number of published cases of spontaneous fits occurring for the first time following ECT concluded that epilepsy as a complication of shock therapy was

Address for reprint requests: Dr DHR Blackwood. MRC Brain Metabolism Unit, University Department of Pharmacology, 1 George Square, Edinburgh.

Accepted 6 August 1980 relatively uncommon and usually self limiting. Recent interest in the relationship between electrical stimulation of the brain and the development of epilepsy has stemmed from the observation by Goddard ${ }^{10} 11$ that repeated subconvulsive electrical stimulation applied to various limbic, olfactory or cortical brain sites eventually leads to the production of stimulation-induced seizures. Goddard termed this effect "kindling" and subsequent work suggested that the kindling process involved a long lasting reduction in convulsive threshold associated with changes in synaptic function both at the site of stimulus and in related brain areas. The aptness of kindling as a model for the study of clinical epilepsy has been enhanced by the findings that the process occurs in many animal species including baboons and rhesus monkeys, that prolonged subconvulsive stimulation eventually causes animals to develop spontaneous seizures and that the effect of electrical stimulation can be mimicked by repeated pharmacological stimulation. ${ }^{12}$ To produce the kindling effect in susceptible brain regions, the stimulations must be spaced in time. Massed stimulations are ineffective. In rats the optimum interval between consecutive stimuli is about 24 hours.

The apparent contradiction between the earlier views that repeated electroconvulsive therapy might protect against spontaneous fits by causing an elevation in seizure threshold and the more recent proposal that repeated, spaced, electrical stimulations might cause epilepsy by a kindling effect was resolved when the critical importance of the time interval between successive stimulations was recognised. Tress et al ${ }^{13}$ reported that in rats the seizure threshold after electroshock 
was elevated for over two hours but returned to normal after 24 hours. Ramer et al ${ }^{14}$ analysed the effect of the between-stimulation interval in rats and observed a kindling effect when electroshock convulsions were given once in three days, contrasted by a steady reduction in response to the same stimulus when applied at hourly intervals.

Goddard ${ }^{10} 11$ warned of the possibility that any form of therapeutic stimulation of the brain might cause epilepsy by a process of kindling, and Pinel $e t$ al $^{15}$ has stressed the wide applicability of kindling and suggested that repeated electroconvulsive treatment could either lead directly to epilepsy or could induce a state of heightened sensitivity to a variety of epileptogenic stimulations in normal or predisposed patients.

Because of the increasing awareness of the potential hazards of spaced stimulation of the brain this study was undertaken to try to estimate the incidence of fits in patients who have been treated by electroconvulsive therapy.

\section{Method}

Subjects Patients who were being studied by one of us (CPLF) in a study of attitudes to ECT ${ }^{16}$ were interviewed separately and asked specifically about symptoms suggestive of epilepsy, and if indicated a clinical examination was carried out. The information obtained by interview was supplemented by examination of hospital case records which were available for all patients. An EEG was offered to all patients who would co-operate but records were finally obtained on only 46 patients. One hundred and sixty-six subjects were interviewed of whom 98 were female and 68 male. The sample comprised 106 patients who had had ECT in 1976 and 60 who had ECT in 1971. The 1976 group were a representative sample of patients under 70 who had at least one ECT course in that year at the Royal Edinburgh Hospital. A total of 183 patients had ECT in 1976. Twelve had died, 25 were over 70, 27 had moved away from Edinburgh. This left 119 available for interview, of whom 106 were contacted. Thirteen patients who were known to be living in Edinburgh, either refused to come for interview or were unable to do so. Four patients in 1971 and 16 patients in 1976 received unilateral ECT ( $1 \%$ of the total sample). All others received the treatment bilaterally. The mean age of all patients was 51.5 years and ranged from 21 to 69 years. The diagnosis of these patients is given in table 1 . Table 2 shows the number of courses of ECT given and table 3 the number of treatments (individual convulsions) received. The mean number of treatments for the group as a whole was 168 (range 1-75) given in 1-14 courses. The
Table 1 The diagnosis of the patients used in this study

\begin{tabular}{lccr}
\hline Diagnosis & $\begin{array}{c}1971 \\
\text { Group }\end{array}$ & $\begin{array}{c}1976 \\
\text { Group }\end{array}$ & Total \\
\hline Unipolar depression & 37 & 67 & 104 \\
Bipolar depression & 10 & 19 & 29 \\
Schizophrenia & 10 & 6 & 16 \\
Hypomania & 1 & 4 & 5 \\
Neurotic & 1 & 4 & 5 \\
Unspecified psychosis & 1 & 3 & 4 \\
Puerperal psychosis & 0 & 2 & 2 \\
Personality disorder & 0 & 1 & 1 \\
Total & 60 & 106 & 166 \\
\hline
\end{tabular}

Table 2 The number of courses of treatment given to patients

\begin{tabular}{llllllll}
\hline $\begin{array}{l}\text { Number of courses } \\
\text { of } E C T\end{array}$ & 1 & 2 & 3 & 4 & 5 & 6 & $>6$ \\
\hline 1971 & 21 & 13 & 11 & 4 & 2 & 4 & 5 \\
1976 & 43 & 23 & 14 & 7 & 6 & 3 & 10 \\
Total & 64 & 36 & 25 & 11 & 8 & 7 & 15 \\
\hline
\end{tabular}

Mean for all patients $=2.4$ treatment courses

Table 3 Total number of treatments given to patients

\begin{tabular}{lrllcc}
\hline Number of treatments & $1-5$ & $6-10$ & $11-20$ & $21-30$ & $>30$ \\
\hline 1971 Group & 2 & 24 & 16 & 9 & 9 \\
1976 Group & 17 & 31 & 31 & 13 & 14 \\
Total & 19 & 55 & 47 & 22 & 23 \\
\hline
\end{tabular}

Mean number of treatments for all patients $=16 \cdot 8$ (range 17-5)

mean length of time between the last course of treatment and interview was 18 months and nobody was interviewed who had not had ECT more than one year previously.

\section{Results}

All patients who reported symptoms suggestive of epilepsy had received bilateral ECT. One female patient described generalised epileptic episodes occurring about once every two years since the age of 12 years for which she had never sought medical advice and which had not become more frequent after ECT. Her EEG in 1978 showed only minor abnormalities in the theta range. One male patient who was alcoholic had generalised fits during the acute phase of a chlorpromazine overdose a few weeks after the completion of a course of ECT. He gave no history of fits at any other time and a subsequent EEG was normal apart from an excess of drug associated fast activity.

Three patients described fits which had occurred for the first time after a course of ECT therapy, when there were no other precipitating factors. 
(1) MB A female aged 56 years with a schizoaffective disorder was treated by four courses of ECT between 1960 and 1963 and two further courses in 1975 and 1976, receiving a total of more than 30 convulsions. She had a single generalised convulsion four hours after the first treatment of the course in 1976. At the time she was taking thioridazine $100 \mathrm{mg}$ thrice daily. An EEG recorded after the fit was not significantly abnormal and one recorded a year later showed only a nonspecific excess of slow waves in the theta range and no paroxysmal changes.

(2) WB A female aged 63 years with unipolar depression who received courses of ECT in 1975, 1976 and 1977 (totalling 18 treatments) experienced two generalised seizures a few days apart, two weeks after her last treatment in 1977. Her drug treatment at the time was amitryptiline $75 \mathrm{mg}$ daily and phenobarbitone $30 \mathrm{mg}$ daily. An EEG was not obtained.

(3) DB A male aged 61 years with bipolar depression was treated by ECT in 1954, 1968, 1970, 1971 (totalling 16 treatments). He had a first spontaneous fit in 1962, eight years after the first course of ECT and had two subsequent episodes of loss of consciousness. His sister was epileptic. He had been treated with lithium carbonate and thioridazine but as far as could be ascertained had not received tricyclic antidepressants. An EEG in 1977 was grossly abnormal with diffuse slow activity but no paroxysmal changes.

EEG findings In no case was paroxysmal activity found. Of 46 records, 26 were considered to be normal and a further 15 contained only nonspecific changes consisting of short-lived runs of excessive theta activity in temporal and occipital regions. This has been recognised as a common finding in a psychiatric population. ${ }^{17}$ The remaining five records showed clear abnormalities consisting of $1-6 \mathrm{~Hz}$ activity which was diffuse in four cases and related to the temporal lobe in one. Of the patients in whom fits had succeeded ECT only one (DB) showed marked abnormality.

\section{Discussion}

A number of studies have attempted to measure the prevalence of epilepsy in the population of England and Wales. Although equivalent figures for Scotland are not available they can be assumed to be broadly similar. Brewis et $a l^{18}$ found a prevalence rate for epilepsy of $5 \cdot 5 / 1000$ based on a detailed survey of the population of the city of Carlisle. In surveys of epilepsy in general practice Pond et al $^{19}$ found a prevalence rate of 6.2/1000 registered patients and a more extensive survey by the Research Committee of the College of General Practitioners ${ }^{20}$ reported a prevalance rate of $4 \cdot 2 / 1000$ for "chronic" epileptics.

These figures almost certainly underestimate the true prevalence and the studies quoted differ in their definition of epilepsy. Pond et $a l^{19}$ included all cases of fits including febrile convulsions, in the two years preceding the survey. Brewis et $a l^{18}$ did not include single fits and the College of General Practitioners ${ }^{20}$ excluded patients who were fit free at the time of the survey.

The number of fits diagnosed in this study was within the expected normal range based on the published prevalence rates for England and Wales. In 166 patients we diagnosed a total of five cases of epilepsy giving a prevalence (with $95 \%$ confidence limits) of $3 \pm 2 \cdot 6 \%$. This does not differ significantly from the prevalence rates found in general practice. It is of interest that in two cases, WB and MB who had no family history of epilepsy, fits had occurred shortly after ECT, although in one case (WB) treatment with a tricyclic antidepressant was a possible precipitating factor. In case 3 (DB) epilepsy appeared to be unrelated to ECT since eight years had elapsed between the time of the first ECT course and first convulsions and 12 further treatment between 1968-71 were not followed by further spontaneous fits.

Blumenthal ${ }^{9}$ reviewed 51 cases and presented a detailed description of his own series of 12 patients (which he considered to be a small proportion of the actual number of patients) who with no previous history of epilepsy had developed fits following ECT. In the reviewed series spontaneous fits occurred from a few hours up to about one year after ECT and in Blumenthal's own patients the average time lapse between the last ECT and the first fit was $2 \frac{1}{2}$ months (range 12 hours to 11 months). Most patients had from one to three epileptic attacks although in one case a patient who had a family history of epilepsy had fits on average once a month for $3 \frac{1}{2}$ years after ECT. The average number of electroconvulsive treatments prior to the first spontaneous seizure was 71 , administered over a period which ranged from five weeks to eight years. The two cases of epilepsy after ECT (MB and WB) reported in this paper appear to have followed a similar natural history to the patients described by Blumenthal.

The role of kindling in the development of human epilepsy remains highly speculative and 
Wada $^{21}$ has stressed the relative difficulty of kindling rhesus monkeys compared to animals such as cats and rodents and he has proposed that humans may be so highly resistant to kindling that the process is not clinically important except in certain predisposed groups of patients. However, Sramka et $a l^{22}$ have reported a case of focal seizures becoming secondarily generalised in a patient receiving thalamic stimulation via indwelling electrodes for the treatment of pain. The development of epilepsy was remarkably reminiscent of the kindling procedure. It is possible that ECT does not lead to epilepsy more commonly because the type of stimulus used is quite unlike the minimal stimulus evoking a local after-discharge which is employed in kindling. It is also possible that a kindling effect during ECT could be inhibited by barbiturates which are routinely used as anaesthetic agents for ECT. In experimental animals barbiturates have a marked prophylactic effect when administered prior to the stimulus during amygdaloid kindling. ${ }^{23} 24$

Biochemical changes which accompany electroshock $^{25}$ and kindling ${ }^{12}$ in rats have suggested involvement of amines in both processes but insufficient is known about the neurochemical changes in specific anatomical sites to make comparisons between the two procedures.

The results of this small survey support the view that ECT may provoke spontaneous fits in a small proportion of patients. However, the number of attacks in each case tends to be small and there is no evidence of an increased incidence of chronic epilepsy in patients who have been exposed to ECT. A knowledge of the neurochemical changes in specific brain sites following electroshock and kindling in animals may lead to a better understanding of the effect on the human brain of spaced stimulation and in particular may make it possible to distinguish the factors which cause an increase in the risk of epilepsy from those factors which are responsible for causing changes in mood.

\section{References}

1 Meduna L, Friedman E. The convulsive irritative therapy of the psychosis. JAMA 1939; 112:501-9.

2 Kalinowski LB, Kennedy F. Observations in electric shock therapy applied to problems of epilepsy. J Nerv Ment Dis 1943; 98:56-67.

3 Taylor JH. Control of grand-mal epilepsy with electroshock. Dis Nerv Sys 1946; 7:284-5.

4 Wolff GE. Electro-convulsive therapy-A help for epileptics. Am Pract Dig Treat 1956; 7: 1791-3.
5 Herberg LJ, Watkins PJ. Epileptiform seizures induced by hypothalamic stimulation in the rat: Resistance to fits following fits. Nature 1966; 209:515-6.

6 Herberg LJ, Tress KH, Blundell JE. Raising the threshold in experimental epilepsy by hypothalamic and septal stimulation and by audiogenic seizures. Brain 1969; 92:313-28.

7 Essig CF, Groce ME, Williamson EL. Reversible elevation of electroconvulsive threshold and occurrence of spontaneous convulsions upon repeated electrical stimulation of the cat brain. Exp Neurol 1961; 4:37-47.

8 Essig CF, Flanary HG. The importance of the convulsion in the occurrence and rate of development of electroconvulsive threshold elevation. Exp Neurol 1966; 14:448-52.

9 Blumenthal IJ. Spontaneous seizures and related electroencephalographic findings following shock therapy. J Nerv Ment Dis 1955; 122:581-8.

10 Goddard GV. Development of epileptic seizures through brain stimulation at low intensity. Nature 1967; 214:1020-1.

11 Goddard GV, McIntyre DC, Leech CK. A permanent change in brain function resulting from daily electrical stimulation. Exp Neurol 1969; 25:295-330.

12 Racine R. Kindling: The first decade. Neurosurgery 1978; 3:234-52.

13 Tress $\mathrm{KH}$, Herberg LJ. Permanent reduction in seizure threshold resulting from repeated electrical stimulation. Exp Neurol 1972; 37:347-59.

14 Ramer D, Pinel JPJ. Progressive intensification of motor seizures produced by periodic electroconvulsive shock. Exp Neurol 1976; 51:421-33.

15 Pinel JPJ, Van Oot PH. Generality of the kindling phenomenon: Some clinical implications. Can J Neurol Sci 1975; 2:467-76.

16 Freeman CPL, Kendell RE. ECT: Patients' experiences and attitudes. $\mathrm{Br} J$ Psychiatry 1980; 137:8-16.

17 Williams D. The significance of an abnormal electroencephalogram. J Neurol Neurosurg Psychiatry 1941; 4:257.

18 Brewis M, Poskanzer DC, Rolland C, Miller $\mathrm{H}$. Neurological disease in an English city. Acta Neurol Scand [Suppl] 24: 1966, Vol 42.

19 Pond DA, Bedwell BH, Stein L. A survey of epilepsy in 14 general practices. I. Demographic and medical data. J Neurol Neurosurg Psychiatry 1960; 63:217-36.

20 Crombie DL, Cross KW, Fry J, Pinsent RJFH, Watts CAH. A survey of the epilepsies in general practice. Br Med J 1960; 2:416-22.

21 Wada JA. The clinical relevance of kindling: Species, brain sites and seizure susceptibility. In: Livingstone $\mathbf{K}$, Hornykiewicz $\mathbf{O}$, eds. Limbic Mechanisms. New York: Plenum Press, 1978: 369-88.

22 Sramka M, Sedlak P, Nadvornik P. Observation of kindling phenomenon in treatment of pain by stimulation in the thalamus. In: Sweet WH, 
Obrador S, Martin-Rodriquez J, eds. Neurosurgical treatment in psychiatry pain and epilepsy. Baltimore: University Park Press, 1977: 651-4.

23 Wise RA, Chinerman J. Effects of diazepam and phenobarbital on electrically induced amygdaloid seizures and seizure development. Exp Neurol 1974; 45:355-63.
24 Wada JA, Sato M, Wake A, Green JR, Troupin AS. Prophylactic effects of phenytoin, phenobarbital and carbamazepine examined in kindled cat preparations. Arch Neurol 1976; 33:426-34.

25 Grahame-Smith DG, Green AR, Costain DW. Mechanism of the anti-depressant action of electro-convulsive therapy. Lancet 1978; 1:254-7. 